\title{
Research on the Challenges and Countermeasures that Nowadays Family Education Confronts
}

\author{
Guo Xiaohua and Han Mengfei \\ $\mathrm{Xi}$ 'an University of Arts and science teachers college,710065
}

Keywords: Enlightenment education, Family education, Mental growth, Parent-child relationship

\begin{abstract}
In recent years, with the fast development of economy, the national living standard has universally improved and the family education has gradually caught people's sight. Good family education is essential for children's healthy growth and remains initial influence that will accompany them for a whole life. In comparison with school education and social education, the family education works in a deep and unintended way which is a necessary enlightenment education in the civilization of human society. Strengthening the research of practical strategy on our nowadays family education will directly influenced development of children's sound personality and healthy psychology, and it is also of great importance to improve the national quality.
\end{abstract}

\section{Problems Existing in New-Period Our Country'S Family Education}

Family education, is an enlightenment education accepted at the beginning of one's life, so it does not play a fundamental role which will set steps for children's learning and life in the future, but also an important process that determines their mental growth and character development. The inner atmosphere, ideology of parents, life style and relationship within parents in any family will subtlety influence the growth of children in all aspects. More often, good family education is more important than school education, because it is a precious wealth for children and will help them to shape a sound personality and a wonderful life. But for now, there are still many universal problems existing in our family education and having adverse influences on way of thinking, passion for study, personality development and other aspects of children. They are harmful to the whole family relationship, either. Therefore, it is very necessary for parents to build a good education concept and master scientific education method. Morever, it determines the healthr growth of children.

\section{Out-dated family education idea}

In modern family education, some parents always become overstressed about their children's future prospects when promoting their education and pay attention on realizing the results that can be predicted or beneficial to children as their wishes, such as a stable and decent work, a happy family and so on. In fact, it is a lack of security in that the parents of the last generation have experienced a turbulent time. So parents pay more attention on knowledge instruction with their children to avoid such kind of security deficiency and regard the exam-oriented education and entrance education as a standard of starting point and final goal, in order to seek a stable and happy future for them. However, they ignore the growth and cognition in emotion and mental of their children, become indifferent with their habits and personal idea and then result the missing of some educations about "intercourse" and "actively thinking" of children. Also, there are increasing number of parents cannot take responsibilities of rational supervision during children's learning and choose to send them to a closed boarding school. And owing to lack of family protection and communication from parents for a long time, the effects run to a reverse direction that children become autistic, traitorous and tired of schooling, even worse, they hate the education environment where they are and the educators. This kind of education pattern has fundamentally killed their thirst for pouring out their heart and accepting understandings while growing up. Besides, there are many parents with less qualified educational level and too many outdated education ideas remain in their mind, they pay too much attention on examination achievements of children and regard the level of results as a key of realizing individual or family's lofty ideal. They push so many pressures of study and psychology on children without considering their feelings and needs that makes 
children cannot study in an active and relaxed way from the fundamental view of their interest point.

\section{Extreme educational methods}

The educational concept change of the new age has rose people's attention on family education and precisely because that leads to various extreme educational methods. For instance, majority parents have been conscious of the importance of an all-round talent in this generation of social competition, so they regardless of money and ignore the pressure of children, force them to attend excessive interest-oriented classes which have caused their school-weariness, and it is a truly spoon-feeding educational method; another example is under the background of family planning, many parents with overindulgence of their only child that results in their habits development of selfcenteredness, and underestimate their cultivation of independence ability. It is a truly "overindulgent" educational method; or parts of the parents lacking of patience and communication toward their education, they hold the belief of "spare the rod and spoil the child". Every time when they are dissatisfied with children' grade or behavior, they beat and scold them and never actively take or accept communication. In a long run, that will easily mislead children to go to a wrong path with rebel psychology, and it is a "clubs" educational method. There are still a lot of similar extreme educational methods; they are all "in the name of love", but demonstrate the abuse of itself from different aspects, and the abuse mainly owing to their not comprehensive educational concept so they can't stand by their children's side to view the problem comprehensively with a clear mind.

\section{One-sided educational view of "prefer to give verbal directions and ignore the teaching by example"}

The biggest one-sidedness of many parents' educational way has shown at their "prefer to give verbal directions and ignore the teaching by example", because they think as long as they are carrying out tireless teaching toward children that they can imbue the idea into their mind, and they do not focus on the process and experience of children's own experiences; instead, they impose too many "general principles" on their children. For these reasons, children do not have enough practical experiences and have no cognition with the society, even worse at distinguishing the wrong and right, thus giving rise to discordance from every aspect of body and mind. Lots of parents are busing with their work and have no time to spare for children's education. There still are part of parents engaging in interaction, leisure and entertainment and ignore the company with children; moreover, they will pass the negative emotion such as impatience and anxiety caused by the recreational life, and then will have bad influence with children's growth from life and emotion. The behavior and language of parents will always unconsciously influence their children's thought and action. When parents are teaching their children while the words are inconsistent with their behavior, the children will feel confused and doubted especially their outlook of right and wrong and value do not complete yet, so as to be suspicious of the education standard from parents and do not know what to do. In the second place, some children will generate resistance psychology in that their parents' words are inconsistent with the practical actions and will eventually stand against this kind of education. The function of preaching by language is limited for a child whose thinking system does not mature yet, while the model practices what he preached can realize a deep memory and understanding for children. Therefore, parents must be patient at this part and combine the verbal directions with teaching by example, make their words to their deeds and build a good model for children in all respects, and use a positive lifestyle and behavior style making good influences on children. Moreover, by means of own rational action to let children accept education in a deeper way.

\section{Skip-generation raising result in the lack of kinship}

In recent years, with the increasing needs for the quality of family living, many parents in the pursuit of making better material bases for children and choose to work busy outside, so they deliver their children to ancestors for caring and education that have ignored different mental traits with different generations and neglected their close communication with parents, either. The previous generation lives in a time when economy, politics, thought and other aspect is totally different with nowadays' society. So, they enjoy a definitely distinguished value and world outlook, and the majority of that time does not accept education and results to an outdated thoughts and ideas. 
On the other side, ancestors' overindulgence with children will make excessive protection on them during the caring. They will try their best to satisfy all their needs and let them overindulgence, without attention on mental, children will gain what they want by losing their temper or making noises whenever they are unsatisfied that will easily resulted in the formation of a wayward but self-contemptuous personality. That kind of personality makes them afraid of facing problems, and once they lose their ancestors' support, they will feel frustrated and hardly accepted. The skipgeneration raising way will cause huge influences with the mental needs, life habits, ideology of children. Although ancestors have rich experiences in life, the limit of knowledge and short of relative understanding with psychology and pedagogy make them easily ignored children's thought education. More frequently, from the perspective of mental needs, what children need most during their childhood is the affection satisfaction, it is an original emotion of human being and do not determine the mental health of themselves, but will pass the health to the next generation. However, the emotion cannot be satisfied with the giving from ancestors, their love lies more on caring about children's physical health and life needs while the needs of mental and spirit lie more on emotional care and psychological care form immediate family toward their children.

\section{Countermeasure Research on Problems Existing in Family Education}

At present, it is universal that all kind of problems existing in family education, and the problem that the majority parents need to reflect by themselves, these problems may influence the whole life of children and their result are irresistible. Aiming at questions above the countermeasures will be put forward at followings:

Optimize the views and ideas of family education

The fundamental idea of family education determines the education method of family and the first mission for optimizing the ideology of family education is to transfer parents' educational idea. During the education process, parents should first abandon their view of attaching much importance to grade and result. Indeed, they should take the quality-oriented education, psychological education and emotional education as key points, combine them with practice and carry out a scientific and systematical family education, fully aware of child will become an independent individual of the society rather than a derivative from parents in the future. Therefore, parents should take a right and patient method to implement education to children and the key point is: listen for children's heart actively, always pay attention on their affective fluctuation and emotional fluctuation, get to know their habits and interests and personal ideal and encourage them to actively achieve. Besides, according to different characteristics of personality in different times of children, parents should make adjustments on educational method, simple favor or simple maltreatment both way too much extreme and cannot have essential education meaning. Only by respecting children's idea and behavior, enhancing mutual communication and actively established democratic and equal relationship in the family, both sides can be better understood. Secondly, parents need to find problems during children's learning and life in time, and use an equal and peaceful way to lead them, promote them to a healthy development road.

\section{Looking at problems in a comprehensive way and implementing education method with multi-angles}

No matter what the" spoon-feeding" education, "overindulgent" education or "clubs" education is, the starting point of parents always originate from their love toward children, but the love should firstly built on respect to them which includes respect with their willing, independent life and personality, and also their cognition process during growth. According to the growth needs of children, parents should give different satisfactions and different criticisms, offer free spaces in their life and help them to build confidence and ability of independent thinking. For study area, parents should seek for gradual improvements and lead them with patience; they cannot simply take coercion policies. It is necessary that parents look at problems in a comprehensive way and implement education method with multi-angles. They can cultivate their interests and habits patiently and can also show their greetings constantly, reprimand children severely when necessary is appropriate, but all of these actions cannot run in an extreme way, any way of extreme education 
will easily lead to an extreme education aftermath.

Practicing the words and growing together

In company with constant forming of children's cognitive competence, they have gradually been conscious to observe and understand people and matters around them, as the closest human relations, parents always directly influenced children's cognition and their words and behaviors have subtle influences with children from every aspect. In consequence, parents should lead by example and practice their words to make a good model for children. In daily life, they should be strict with themselves and affect their children with reasonable behaviors so as to grow with them together, the simple preaching for children and wishes for them to become outstanding talents while parents be negative and do not pay efforts will make children feel themselves are the only one who work hard so as to lose their enthusiasm.

\section{Avoiding the disadvantages of skip-generation raising}

The largest disadvantage of the skip-generation raising is the lack of affection and different educational goal in different time. Although the material bases in family is of great importance, for children, the lack of affection in childhood will become an irreparable regret for a whole life. In addition, various kinds of character problem and mental problem are brought by an outdated educational method when children are getting along with their ancestors. So, parents should pay more attention on children after work and participate in the process of their growth and education, it will not only beneficial to form their mental health, but also in favor of benign development of parent-child relationship.

\section{Conclusion}

Family education, as an important part of the education career, is of vital importance for education of our whole nation. In children's growth process, parents should take proper educational methods, pay attention on moral and ability development of children, create a happy family atmosphere, build a right concept for family education, make children truly understand the real meaning of it so as to accept education with their own willing in a deeper way.

\section{Acknowledgement}

Fund Project: National College Students' innovation and Entrepreneurship Project "Study on the current situation and problems of Xi'an grandparenting"

Project Number: 201711080021

\section{References}

[1] Methods of Modern Family Education, Ding Jiliang, Jiangsu University Press. 2014

[2] Family Education and Parents Education, Chen Heqin, Shanghai People's Publishing House, 2016

[3] The Research Library of Chinese Family Education: Family education Sociology. Guan Ying, Science and Education Press, 2014

[4] Montessori Family Education Book, Montessori, China Business Press.2013

[5] Happy Family Education of Waldorf, Harvey Zahra. Taihai Publishing House, 2015

[6] Best Family Education for Children, Wang Xiuwen, Zhejiang Education Publishing House. 2011

[7] Observation of Chinese Family Education: Zhao Zhongxin Interview Records, Zhao Zhongxin. Academic Press, 2013

[8] Eight Key Points in Family Education for Children from 0 to 3, Wei Yu. Guangxi Normal University Press.2015

[9] Be the Right Parent: Breakthrough the Confusion in Family Education, Leonard Sachs. China Youth Publishing House, 2016 
[10] Charlotte Mason's Family Education Method, Charlotte Mason. Hubei Children's Publishing House. 2015 